\title{
A Study on Development and Application of Island Type Water Balance Evaluation System
}

\author{
Seongjoon Byeon ${ }^{1}$, WooSung Cho ${ }^{1}$, KyungSu Lee ${ }^{2}$ and Ji Woong Hwang $1^{*}$ \\ 1 International Center For Urban Water Hydroinformatics Research \& \\ Innovation (ICUH), 169 Gaetbeol-ro, Yeonsu-gu, 406-840 Incheon, Korea \\ 2 National Disaster Management Institute(NDMI), 136 Mapo-daero, Mapo-gu, \\ 121-719 Seoul, \\ E-Mail: fwangji0306@naver.com \\ Tel.: +82-32-850-5722; Fax: +82-32-851-5730
}

\begin{abstract}
Korea repeatedly experiences floods and droughts that cause traumatic environmental conditions with huge economic impact. With an approach and solution such as Smart Water Grid these problems can be alleviated. Tapping into the retention ponds behind dams, rainfall harvest facilities in urban areas and any other structures installed to store rainfall water during flood events will mitigate the damage of flooding and provide a new source of national water resources. Similarly, purified waste water, ground water and desalinated sea water can also be feasible to use as alternative water resources.

In this study, the water balance assessment model is being developed as a Smart Water Grid research. In fact, large proportions of water resources in Korea rely on a river fresh water. Also in the Youngjongdo island, tap water from water purification plant which use original source from the Han river. However the water supply system in the island is quite dangerous since the water purification plant is located in Incheon city and the water comes to island through the sea and no other source is used in the island. Therefore, once the accident at main water pipe in the sea, no water is available in this island.

Information on water availability and water needs are crucial to identify hot spots of quantitative pressures on water resources. In this study, all available alternative water sources are calculated by the model developed through this study. Several physical and stochastic models on hydraulic and hydrological approaches are nominated to investigate physical characteristics of catchments
\end{abstract}

Keywords: Water Balance, IWRM, Smart Water Grid

\section{Introduction}

Korea repeatedly experiences floods and droughts that cause traumatic environmental conditions with huge economic impacts. The water resource environment of Korea is changing rapidly due to climate change. For example, the rainfall pattern has changed and its term has become increasingly concentrated. Therefore, the water resource environment of Korea, being rainfall, is increasing in the central district and decreasing in the southland part. In addition, some areas have problems, such as water shortages and water distribution. The abovementioned problem is not only Korean one but a global issue. Globally, there are still more than 1.5 billion people with no access to safe water and 2.6 million people faced with a lack of sanitation facilities that provide clean water. In particular, in developing countries, unreliable water from poor treatment facilities causes several health problems, which can occasionally be linked to serious diseases. There is also a problem with the water itself which gradually becomes polluted because of the lack of treatment facilities [1]. 
According to the water movement through the hydrological cycle, the total quantity of water is always constant and unlimited. Nevertheless, the quantity of water as an essential resource is quite limited because it is difficult to meet the quality of water for the necessary purpose within the natural status. Therefore, many activities are needed to preserve the essential water resources and the huge domain of Integrated Water Resources Management (IWRM) concept has been developed [2-3]. IWRM approaches involve applying knowledge from a range of disciplines as well as the insights from diverse stakeholders to devise and implement efficient, equitable and sustainable solutions to water and development problems. Therefore, IWRM is a comprehensive, participatory planning and implementation tool for the management and development of water resources in a way that balances the social and economic needs, and ensures the protection of the ecosystems for future generations. In such an approach, ICT solutions can play a key role but should focus on the most demanding and relevant domains of the water cycle.

Reasonable correspondence considering climate change within the activities and cycle above is needed. Moreover, to secure an additional headspring, expanded facilities have mainly been utilized, and climate change was not considered. This study focused simply on the water supply system and unity water treatment system. Therefore, one integrated and effective water management with low-energy and high-efficiency is needed. The Smart Water Grid (SWG) can make use of local IT skills with a global level to solve this problem, which can lead to the generation of a green water industry.

To overcome the limitations of the existing water resources management system, the SWG appeared, which is an intelligent water management system, combined with most up-to-date technology of information and communications (ICT: Information Communication Technology).

Innovation in the Information and Communication Technology (ICT) is driven by unbroken progress in the hardware performance for the processing number, storing data and growing network capabilities, and wired and wireless technology. A new member in this story is the sensor for the physical, chemical and biological quantities, and qualities that when integrated in communication and networking, opens the door to the vision on the Internet of Things [4]. The ability to interact with objects can be altered remotely based on the immediate or present needs, in accordance with the existing enduser agreements [5].

Within the situations faced in several regions and solution technologies, to highlight the necessary and the first element to secure water for humans, it is important to know the water situation in the region, such as the level shortage and how to secure more water. This study focuses on the island region because islands are easily isolated, particularly in terms of the water supply unless they have their own stable water source and water distribution system. A few islands that have bridges connected to the mainland can take water from the inland but the proportion of those islands is small. Although there are alternative water resources, such as ground water, harvested rain water, desalinated sea water, this type of water supply accompanies has disadvantages, such as significant noise pollution, high power consumption, low water quality, salt water intrusion. Therefore, island regions occasionally face difficulty in securing sufficient water and require certain assessment data to make their decision to secure water.

According to the Korean Statistical Information Service, there are more than 3,200 islands in Korea and approximately 400,000 persons are living in these 470 islands [6]. This study provides basic data to secure water for a pilot island as the study area.

This study examined the overall framework in terms of a water balance assessment in island regions from the methodologies to the solutions to resolve the physical and potential water shortage problems. To understand the definition and the application of this framework proposed through this study, it is also necessary to understand the concept of the Smart Water Grid and the Hydro informatics in terms of their theoretical approach and 
solutions based on them. Therefore, this study was conducted as a part of developing a Smart Water Grid and is based on the concept of Hydro informatics.

Therefore, it is essential to make an accurate assessment of the water supply and demand of the grid for water provision for an essential market at the right time and correct amount. For a long term perspective, an assessment system will be developed, which can evaluate and solve water shortage of a city including industrial water and agricultural water using an automation technique.

\section{Smart Water Management Concept}

\subsection{Water Cycle Improvement with Smart Water Grid}

A smart water grid is a network that uses ICT to gather and act on information generated by suppliers, consumers and devices in an automated fashion to improve efficiency, reliability, economics and sustainability of production and distribution. Briefly, it uses sensors (meters), digital communications, and embedded digital processing to make the grid observable (able to measure the states of all grid elements), controllable (able to affect the state of any grid element) and automated (able to adapt and self-heal). A smart grid's functionality [9] will (1) enable active participation by consumers, (2) accommodate all production, distribution and storage options, (3) enable new products, services and markets, (4) provide water quality for the digital economy, (5) optimize asset utilization and operate efficiently, (6) anticipate and respond to system disturbances, (7) operate resiliently against attack and natural disaster. Figure 1 shows the strategic concept for securing water resources through improvement of water cycle as one of concept of smart water grid [7].



Figure 1. Concept of Water Cycle Management System Improvement

\subsection{Target Region and its Application}

In this study, the water balance assessment model is being developed as a Smart Water Grid research. In order to decide the target region for smart water balance assessment system, 3 different scales for major system and 1 overseas type have been defined as shown in the Figure 2. 

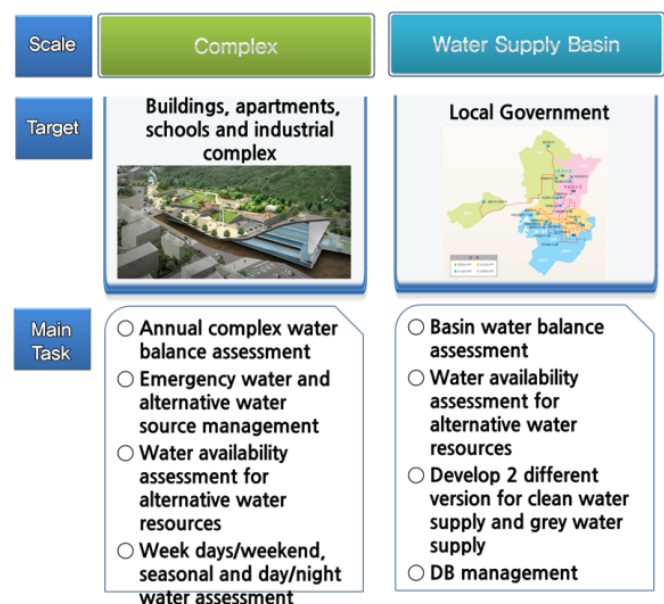



\section{Figure 2. Targets for System Development and Main Task for Each Scale}

In fact, large proportions of water resources in Korea rely on river fresh water. Also in the Youngjongdo Island, tap water from water purification plant which use original source from the Han river. However the water supply system in the island is quite dangerous since the water purification plant is located in Incheon city and the water comes to island through the sea and no other source is used in the island. Therefore, once the accident at main water pipe in the sea, no water is available in this island as shown in the Figure 3.

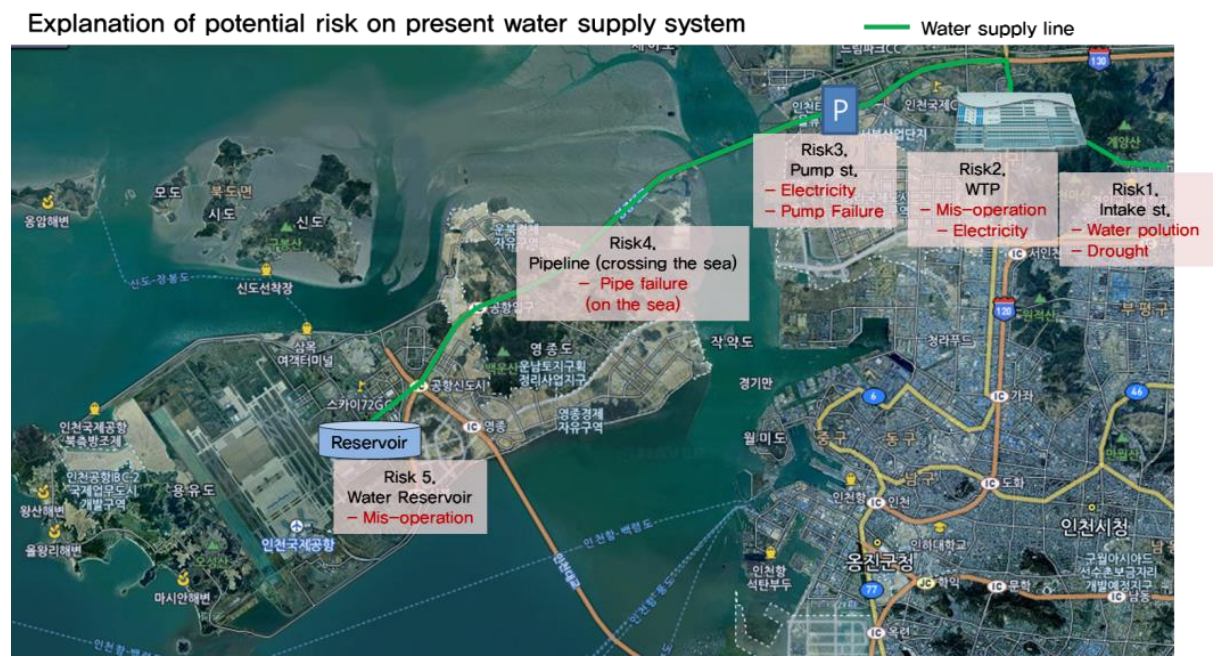

Figure 3. Potential Risk on Present Water Supply System of the Youngjongdo Island

Development of water balance assessment system. To replace the system with potential risks, new concept of smart water management for region with water stress has been created through the field work as well as active discussions on conceptual assumptions to improve. In this study, all available alternative water sources are discovered and calculated. Figure 4 shows the concept for smart water management in this complex and also shows how to overcome the potential risks. 


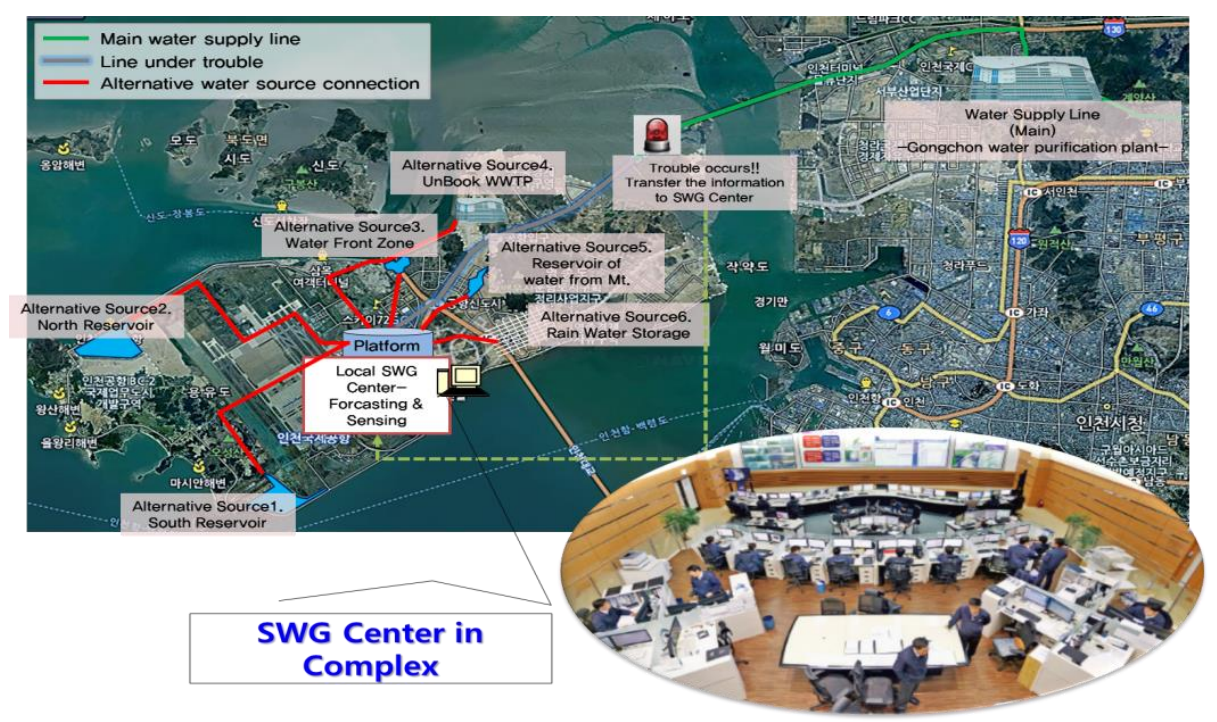

Figure 4. Concept of Smart Water Balance Assessment and Multi-Source Connection

Several physical and stochastic models on hydraulic and hydrological approaches are nominated to investigate physical characteristics of catchments. 9 major modules are connected in the system and each module also can be independent software to calculate the real situation as shown in the Figure 5.



Figure 5. General Framework for Components of a Modeling Tool

There are two major parameters, water supply data including drinking water and nondrinking water, and three types of water demand data within purpose of domestic, industrial and agricultural use. Some of them require modeling modules and the others can be obtained from planning or designing documents that are stored in the database. One important consideration is the water supply from official waterworks. This is water treated through a water purification plant and its source is external water resources, such as rivers or dams. This is very stable and normally sufficient because it is designed to cover an entire domain with a surplus portion. On the other hand, it occasionally covers 
more than one region with a complicated network and has risks at the source itself or the pipe line. Therefore, it is essential to secure self-sufficient water resources from internal sources in the domain to cover the potential risks, especially in island regions.

The previous types of models have limited functions for catching the problems associated with the water cycle because of the separate modeling on different cycles of water and very wide scale of the domain, such as a whole major river basin, a metropolitan province or wide watershed. Moreover, those models basically do not consider multiple water sources. On the other hand, this study attempts to develop a model to cover all the necessary procedures upon resolving a problem encountered at previous models, as listed in table 1 .

Table 1. General Comparison of this Model with Previous Models

\begin{tabular}{|c|c|c|}
\hline Issues & Previous models & This study \\
\hline Scale & $\begin{array}{l}\text { River basin } \\
\text { Wide watershed } \\
\text { Metropolitan province }\end{array}$ & Micro scale (up to $1 \mathrm{~km}^{2}$ ) \\
\hline $\begin{array}{l}\text { Catchment } \\
\text { Type }\end{array}$ & Urban or Rural & Urban and rural \\
\hline ion ${ }^{\text {Standardizat }}$ & Separated modules & $\begin{array}{c}\text { Integrated } \\
\text { standardization }\end{array}$ \\
\hline Integration & Integrated with climate data & $\begin{array}{l}\text { Integrated with climate data, multiple } \\
\text { water sources and all smart water grid } \\
\text { components (sensor, platform and } \\
\text { waterloop etc.) }\end{array}$ \\
\hline
\end{tabular}

This system basically provides a water balance with the total water resources available and the total water demand. This is purely a quantity wise water balance that can occasionally provide the state of the water balance as sufficient regardless of the water use that needs to secure sufficient water quality, such as drinking water. Therefore, each water resource from the simulation or user specification is available to choose the purpose of water. For example, ground water, desalinated sea water and stream water can be used for all water uses but collected rain water at the retention pond, treated waste water and gray water can be used only for agricultural water and partially for industrial water unless the water is used as the material of a food product. On the other hand, the description from the example above is not always the truth but it is just a common sense because the water quality of the sources is always variable and it occasionally depends on the method of the water treatment. In addition, there is another issue regarding the quantity of water from the source. Sometimes a source in the domain can supply very little water and it requires a huge pipe line and treatment facility, which can easily occur. Moreover, the source may be excluded from the selection unless it is the only source to take water. Therefore, this module allows the users to specify each source if it is used and the purpose of water use. The water balance is provided as a graphical view, as shown in Figure 6 .

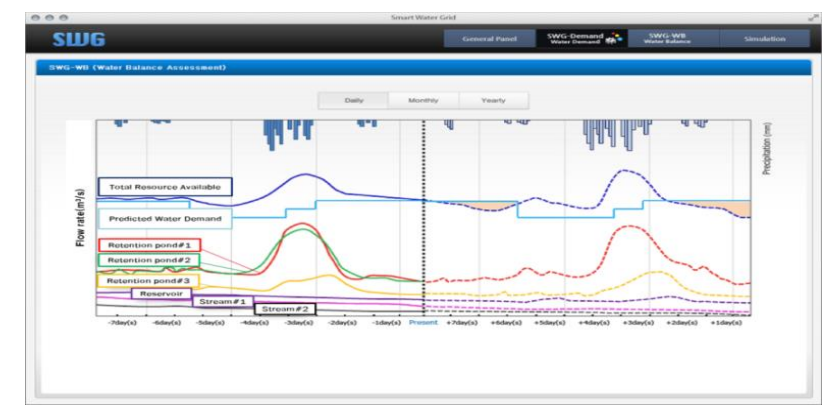

Figure 6. Chart Interface for a Water Balance Assessment 
Within the interface of the model, the results from modeling and the water balance can be displayed. For the data composition, all data can be inputted on a GIS-based interface, all predicting procedures including modeling are automatically done shortly afterward revising the data. Figure 7 presents the basic interface of the model.

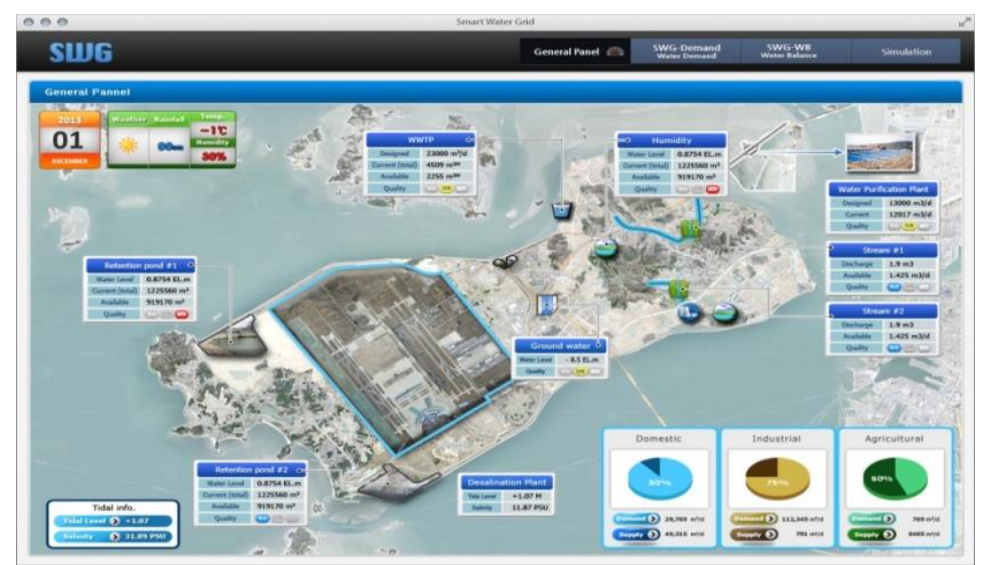

Figure 7. General Interface to Display the General Result from the Model

\subsection{Water Resources Calculated through this System}

The model developed for this study generated 11 sub catchments through an analysis of the surface elevation of the island. Inland water to sea from the Incheon International Airport is drained through three control points, such as the North, South and East reservoirs, so the airport zone is divided into three sub catchments. A sub catchment covering the Donggang stream, which is a small river flows across the eastern part of the island is also divided into two different catchments because there is Unbuk reservoir, which is an irrigation reservoir and a compulsory point to check the agricultural water use. Therefore, the catchments for the Donggang stream are the sub catchment of Unbuk reservoir and the sub catchment of lower Donggang. The model separates a catchment for the Unbuk Waste Water Treatment Plant. Figure 8 shows the divided sub catchment in the island. Table 2 lists the annual water resources available calculated through this modeling system at each sub catchment and the annual runoff on each control point. This data set can be used to provide basic information to calculate the water resources available in the whole domain.



Figure 8. Subcatchments in Yeongjongdo Island 
Table 2. Summary Table on Rainfall Runoff Modeling

\begin{tabular}{clll}
\hline $\begin{array}{c}\text { Sub- } \\
\text { basin }\end{array}$ & Characteristics & \multicolumn{2}{l}{ Annual Runoff $(1,000 \mathrm{~m} 3)$} \\
\hline NS & Incl. North Reservoir & 2024 & 2025 \\
SS & Incl. South Reservoir & 68,221 & 44,306 \\
ES & Incl. East Reservoir & 65,042 & 37,454 \\
YB & IFEZ Yeongjong (planned) & 39,796 & 26,698 \\
YBO & Incl. Unbuk WWTP & 9,271 & 3,387 \\
DG & Donggang stream & 8,182 & 4,985 \\
YS & Unseo Newtown & 16,217 & 9,789 \\
DC & Milano Design City & 33,420 & 21,280 \\
YJ & IFEZ Yeongjong (developed) & 9,029 & 5,374 \\
YJO & Adjoins IFEZ Yeongjong & 42,457 & 26,577 \\
\hline
\end{tabular}

\section{Summary and Conclusions}

This study discusses a novel water balance assessment model which is being developed as a part of smart water grid project in Korea. And following conclusions show the summary of the study.

1) The concept of water balance assessment is overcoming water shortage risk and enlarging the self-sufficiency rate of water through the connection of multi-sources such as desalinated sea water, treated waste water, ground water, harvested rain water and so on;

2) A complex type water balance assessment model has been developed within flow control and 9 different modules and;

3) The Youngjongdo Island has been chosen as $1^{\text {st }}$ case study for the system since it has unique water supply system which providing purified water through the sea with several risks.

4) This study suggested simple and fundamental directions to apply smart water management technologies for the island region, which can cover the water for nondrinking purposes in the ordinary state. In addition, the smart water management system was found to be able to counter the potential problems with the water supply system that cause short-term water cutting off.

Smart water grids are a challenge to research and business. They may be seen as embedded activity towards the future water management.

\section{Acknowledgement}

This research was supported by a grant (12-TI-C01) from Advanced Water Management Research Program funded by Ministry of Land, Infrastructure and Transport of Korean government.

\section{References}

[1] S. Byeon, "Development of Water Management System for Stable Water Supply in Isolated Region", ph.D. dissertation, Incheon National University, Korea (2015).

[2] P. Gourbesville, 2014, "Hydroinformatics challenges and ways to overcome them", 11th International Conference on Hydroinformatics HIC 2014, New York, USA.

[3] T. Jønch-Clausen, 2004, "Integrated Water Resources Management (IWRM) and Water Efficiency Plans by 2005", Global Water Partnership, Sweden. 
[4] K.P. Holz, 2013, "Hydroinformatics contribution to smart water grid", Smart Water Grid International Conference 2013, Incheon, Korea, CD.

[5] Wikipedia, 2014, Internet of Things, http://en.wikipedia.org/wiki/Internet_of_Things.

[6] MOSPA, 2011, "General state of coast line and islands", Korean Statistical Information Service, Korea.

[7] S. Byeon, G. Choi, S. Maeng and P. Gourbesville, 'Sustainable water distribution strategy with smart water grid”, Sustainablilty, vol. 7(4), 4240-4259 (2015).
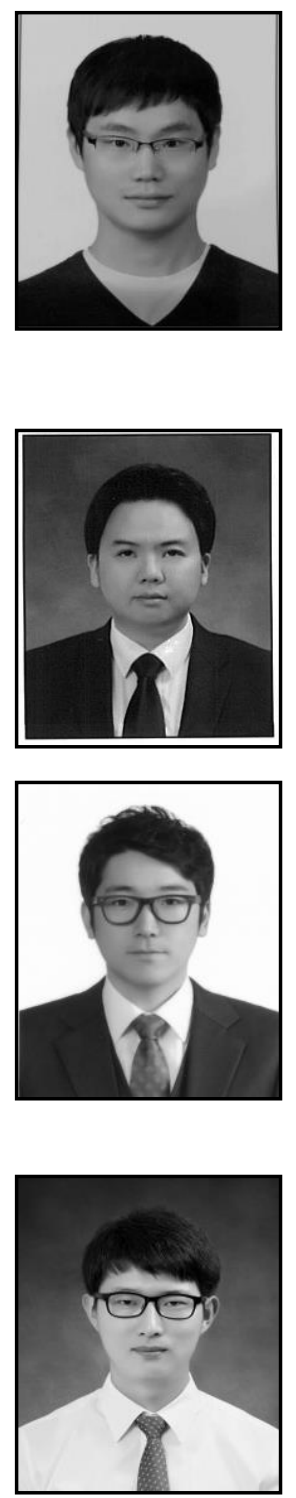

\section{Authors}

Seong Joon Byeon, he received his BSc degree in Civil Engineering, his M.S. degree and Ph.D. degree in Hydroinformatics from Incheon National University, Korea, in 2005, 2008 and 2015 respectively. He has also received his M.S. degree and Ph.D. degree in EuroAQUAE Hydroinformatics from University of Nice Sophia Antipolis, France in 2007 and 2014. His research interest is convergence of computer science and water engineering.

Woo Sung Cho, he received his BSc degree in Civil Engineering and his M.S. Degree in Hydroinformatics (Engineering) from Dong-Eui University, Busan, Korea, in 2012 and 2014 respectively. His research interest is convergence of computer science and water engineering.

Kyung Su, Lee, he received his Master's degree in Civil Engineering (River and Hydraulics Engineering) from Korea National University of Transportation, Chungbuk, Korea, in 2012. And, he completed a Ph.D. degree program at the Korea National University of Transportation Chungbuk, Korea. His Research Interest is Water Resource, River Engineering, and Scientific Disaster Investigation. (E-mail: 39lks@korea.kr / 39lks@ hanmail.net)

Ji Woong Hwang, he received his B.S degree in Civil Engineering and his M.S. Degree in Hydraulic Engineering from Sang-Ji University, Wonju, Korea, in 2012 and 2014 respectively. His is doing research Environment, Hydraulic, Prevention of Disaster, Modeling at the ICUH(International Center for Urban Water Hydroinformatics Research \& Innovation), Incheon, Korea. 
International Journal of Control and Automation Vol.8, No.10 (2015) 